\title{
Reducing the Effect of the Atmospheric Disturbance on Longitudinal Fight Control System Usage PID Controller
}

\author{
Muna Hadi Saleh, PhD \\ Assist. Prof \\ Department of Electrical Engineering / College of \\ Engineering /University of Baghdad
}

\author{
Noor Abdul Razzaq Raheem \\ Department of Electrical Engineering / College of \\ Engineering /University of Baghdad
}

\begin{abstract}
Autopilot systems have been vital to flight control for several years and have been making flight easier and more effective. Nevertheless, these autopilot systems are complex devices that demand exact control and stability. In this paper, design PID controller to control pitch angle in longitudinal dynamic of the autopilot system for jet transport using MATLAB/SIMULINK. In this paper designed on automatic pilot with Multi Input Multi Output (MIMO) system. Also, we studied the effect of atmospheric disturbances when a PID controller has been applied the results shown how this controller with good tuning reducing the effect of atmospheric disturbance on the consistency of the autopilot.
\end{abstract}

\section{Keywords}

Longitudinal Autopilot, Pitch angle, Atmospheric Disturbance, Flight Control, PID

\section{INTRODUCTION}

The autopilot is a system planned to lead a vehicle without an assist. Due to increase in flight hours and complexity of modern day flight it become necessary to provide aircraft with autopilot. Thus dependability and uniformity of an autopilot system become a pivotal role in a flight. The increased complexity and request to premium accuracy has made the procedure of evaluating the autopilot for consistency a difficult process. They involve complex control systems with robust computing equipment [1].

Furthermore, PID controller and autopilots have been successfully unified as real-time control and online navigation systems. This is not only because of the simple construction and easy to implement, but also suitable for their actions. However, for the successful implementation of such control, no need for complex mathematical development, parameter adjustment or make an adjustment if the performance improvement reached during playback mode, [2].

In this paper, the first part we explain the basic parts of the aircraft and the flight principles. In the second section, longitudinal dynamic modeling of the jet transport aircraft will be delivered. In the third section we explain the force of atmospheric disturbances on the constancy of the aircraft. Then the public presentations of full PID control configuration will also be designed. Then discuss the results of this configuration.

\section{BASIC AUTOPILOT FUNCTION}

The autopilot system consists of two parts guidance and command purposes. The guidance function of an autopilot limits the course and the speed to be succeeded by the aircraft. This is done by measuring the current actual values and comparing them to the character. The control mapping is the role that gets the data from the guidance system and puts on the suitable corrections. The control loops ensure a speed and stable response of the aircraft to the commands created by the guidance loops as shown in Figure (1). They must as well get rid of the influence of external disturbances. The autopilot structure can be divided into internal and outer loops. The control loop (inner loop) it is controlled by the guidance system (outer loop) [3].

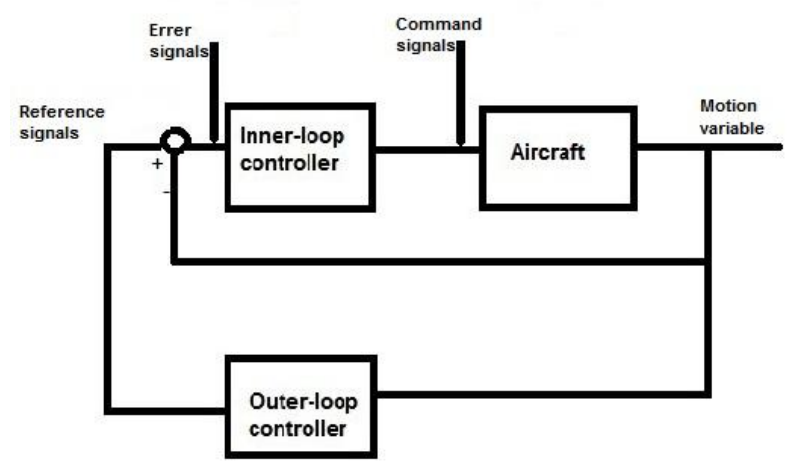

Figure (1) Guidance and Control Purposes

The automatic pilot is Multi input Multi output (MIMO) system, and then it is major to describe the relationships between them. These relationships are regulated by the transfer functions of airframe, which provides the lowest and most important imaging the dynamics of the airframe. They describe the command-response relationship as an occasion of aerospace condition and may carry the effect of atmospheric disturbances. These basic relationships are illustrated in Figure (2). Central to this structure is a mathematical model of the plane which is commonly cited to as the Equations of Motion (EOM). The equations of motion deliver a perfect explanation of response to controls; subject only to modeling limitations defined at the beginning, and is evaluated in terms of displacement, speed and acceleration. The aerospace condition describes the conditions under which the clarifications are caused and includes elements, such as altitude, aircraft geometry, mass, Mach number and trim state. When the airframe is added to a course control system the equations of motion are revised to model this arrangement. Transfer functions response, derived from the mathematical solution of the equations of motion, are after no longer the basic aerodynamic transfer functions but are obviously the transfer functions of the improved airplane [4]. 


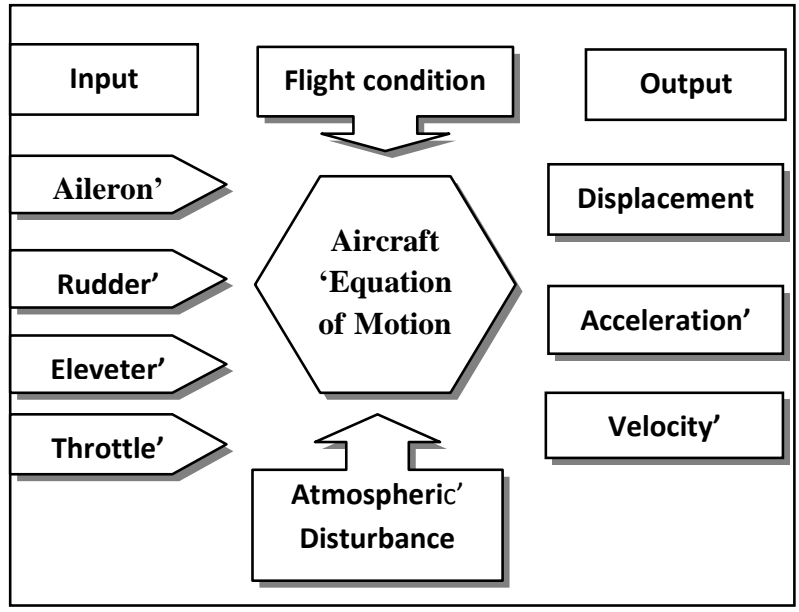

Figure (2): Autopilot control system

The inputs to the model are the control surface deflections $\left(\delta^{\prime}\right)$ aileron, rudder, elevator and throttle. When the lifts are used in the plane pitch up or down, causing it to climb or dive. And ailerons used to deploy the aircraft. Thus rudder turn right or left the aircraft and the so-called yawing as is apparent in Figure (3). There are three axes of motions lateral, longitudinal and vertical axes. The lateral axis passes through the plane from wingtip to wingtip. Rotation around this axis is the pitch. Pitch change the vertical guidance that shows the nose of the plane. The elevators are the primary control surfaces for pitch, the longitudinal axis, badges through the plane of the nose to rise. Revolution about this axis is called roll. Rolling motion to change the direction of the aircraft wings with respect to the landing of the force of gravity.

Pilot change the roll angle by increasing the lift on one wing and downgrades on the other hand. This causes a rotation differential bank raised about the longitudinal axis. The ailerons are the main control to roll. Rudder also has a secondary effect on the West. The vertical axis passes through the plane from top to bottom, and this is called rotation around the yaw axis. Yaw change the direction the nose of the plane points out, to the right or the left. Yaw in the main control is with the rudder. Ailerons also have a secondary effect on yaw.

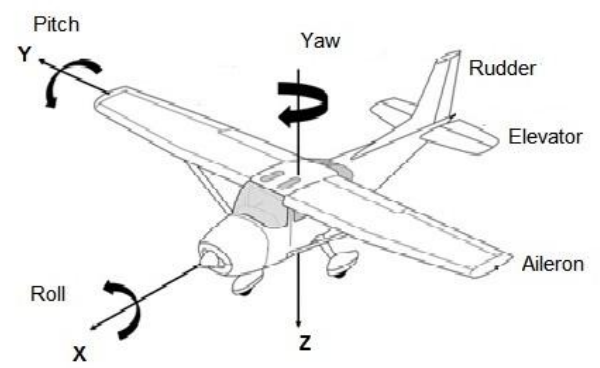

Figure (3): External components of the aircraft

\section{LONGITUDINAL AUTOPILOT MODE}

Longitudinal autopilot model consist of two parts the elevator and the throttle. The elevator is used to control pitch angle, pitch rate and acceleration while throttle is used to control vehicle speed. The complete block diagram for the longitudinal control system to jet transport aircraft .The system consist of four channel, Multi Input Multi Output (MIMO) as shown Figure (4). If the pitch attitude varies from the reference, a voltage egg is brought out by the signal generator on the vertical gyro. This potential difference is then expanded and run to the elevator servo. The servo actuators are used to ward off the aerodynamic control surfaces. This value then is conveyed with the elevation as well as the pitch angle $(\theta)$ and served in the control blocks of the diagram. It should be noted that the gains shown in the feedback system variable rings and completely dependent on the speed of the aircraft [5]

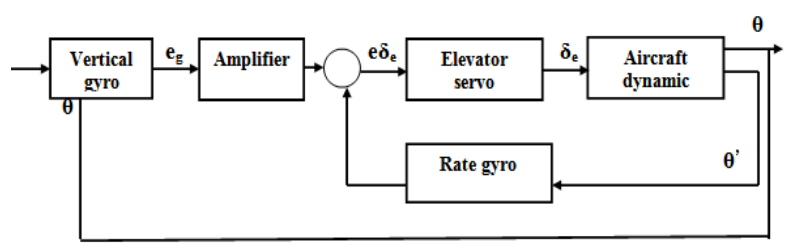

Figure (4): Autopilot longitudinal control system

In longitudinal dynamics of the jet transport aircraft, linearized and Laplace transformed Equation of Motion (EOM), has been used for analysis as given in equation below (1), where the first two are force equations in $\mathrm{X}$ and $\mathrm{Z}$ directions, while $\mathrm{M}$ is moment equation in my direction, and taken from [6].

$\mathrm{X}^{\prime}:\left(\frac{m u}{S q} \mathrm{~s}-\mathrm{C}_{\mathrm{xu}}\right) \mathrm{u}^{\prime}(\mathrm{s})-\mathrm{C}_{\mathrm{Xa}} \alpha^{\prime}(\mathrm{s})-\mathrm{C}_{\mathrm{W}}(\operatorname{COS} \Theta) \theta^{\prime}(\mathrm{s})=0$

$\mathrm{Z}:-\mathrm{C}_{\mathrm{zu}} \mathrm{u}^{\prime}(\mathrm{s})+\left[\left(\frac{m u}{S q}-\frac{\mathrm{c} \cdot \mathrm{Cz} \alpha^{\prime}}{2 u}\right) \mathrm{S}-\mathrm{C}_{\mathrm{za}}\right] \alpha^{\prime}(\mathrm{s})+\left[\left(-\frac{m u}{S q}-\right.\right.$ $\left.\left.\left.\frac{\text { c.Czq }}{2 u}\right) \mathrm{S}-\mathrm{C}_{\mathrm{W}} \sin \Theta\right)\right] \theta^{\prime}(\mathrm{s})=0$

$\mathrm{M}^{\prime}:\left(-\frac{c \cdot C m \alpha^{\prime}}{2 u} s-C m \alpha\right) \alpha^{\prime}(s)+\left(\frac{\mathrm{Iy}}{S q c} S^{2}-\frac{c \cdot C \mathrm{mq}}{2 u} S\right.$

$\theta^{\prime}(s)=0$

Where

Ù =Variation of velocity in longitudinal flight, $\mathrm{u}=\mathrm{u} / \mathrm{u} 0$

$\alpha^{\prime}=$ Variation of angle of attack in longitudinal flight, $\alpha=\mathrm{\alpha} / \mathrm{u} 0$

$\theta^{\prime}=$ Variation of pitching angle from the equilibrium condition

The characteristic properties of jet transport aircraft and stability derivatives are shown in Table (1) and (2) respectively which calculated in [6]

Table (1): Characteristic properties of jet transport aircraft in longitudinal mode

\begin{tabular}{|ll|c|}
\hline \multicolumn{2}{|c|}{ Symbol } & Quantity \\
\hline $\mathrm{m}$ & mass & $5800 \mathrm{slug}$ \\
\hline $\mathrm{U}$ & steady state velocity & $600 \mathrm{ft} / \mathrm{sec}$ \\
\hline $\mathrm{S}$ & wing air & $2400 \mathrm{sq} \mathrm{ft}$ \\
\hline $\mathrm{P}$ & air density & 0.000585 \\
\hline $\mathrm{I}_{\mathrm{y}}$ & moment of inertia & $2.62 * 10^{6}$ slug $\mathrm{ft}^{2}$ \\
\hline
\end{tabular}


Eq. (1) Becomes:

$$
\begin{aligned}
& (13.78 \mathrm{~s}+0.089) \mathrm{ù}(\mathrm{s})-0.3923 \alpha \dot{\alpha}(\mathrm{s})+0.74 \theta^{\prime}(\mathrm{s})=0 \\
& 1.49 \mathrm{u}(\mathrm{s})+(13.78 \mathrm{~s}+4.45) \dot{\alpha}(\mathrm{s})-13.78 \theta^{\prime}(\mathrm{s})=0 \\
& (0.0551 \mathrm{~s}+0.619) \dot{\alpha}(\mathrm{s})+\left(0.513 \mathrm{~s}^{2}+0.193 \mathrm{~s}\right) \theta^{\prime}(\mathrm{s})=0
\end{aligned}
$$

Table (2): Stability Derivatives and Input of Aircraft in Longitudinal Mode

\begin{tabular}{|l|l|}
\hline \multicolumn{1}{|c|}{ Symbol/ Quantity } & \multicolumn{1}{|c|}{ Symbol /Quantity } \\
\hline $\mathrm{C}_{\mathrm{xu}=}-0.888$ & $\mathrm{C}_{\mathrm{m} \alpha}=-0.619$ \\
\hline $\mathrm{C}_{\mathrm{xa}=} 0.392$ & $\mathrm{C}_{\mathrm{m} \alpha^{\prime}}=-3.27$ \\
\hline $\mathrm{C}_{\mathrm{mq}}=-11.4$ & $\mathrm{C}_{\mathrm{zu}}=-1.48$ \\
\hline $\mathrm{C}_{\mathrm{zq}=-0.394}$ & $\mathrm{C}_{\mathrm{z \alpha}}=-4.46$ \\
\hline $\mathrm{C}_{\mathrm{W}=-0.74}$ & $\mathrm{C}_{\mathrm{za}}=-1.13$ \\
\hline
\end{tabular}

We arrange these equations (2) on the matrix and get the determinant

$$
\begin{aligned}
& \begin{array}{cc|c}
13.78 s+0.089 & -0.3923 & 0.74 \\
1.49 & 13.78 s+4.45 & -13.78 \\
0 & 0.0551 s+0.619 & 0.513 \mathrm{~s} 2+0.193 \mathrm{~s}
\end{array}=0 \\
& s^{4}+0.811 s^{3}+1.32 s^{2}+0.01 s+0.0068=0
\end{aligned}
$$

Then using synthetic division to obtain two quadratic factors

$$
\left(S^{2}+0.004 S+0.005\right)\left(S^{2}+0.806 S+1.32\right)=0
$$

Then calculated the natural frequency $\mathrm{Wn}$ and damping ratio $z$ to equation. (5) From:

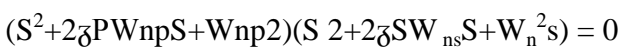

\section{ATMOSPHERIC DISTURBANCE ON AUTOPILOT}

The study of flight is usually divided into two groups: atmospheric and space flight system. The two have developed separately over the last period. Atmospheric disturbances undesirably influence aircraft motion and flying safety. The estimate of getting the aircraft response and the equivalent loads in gusts and turbulence is not novel. In that situation were some possible challenges in the previous to use active control technology to counteract atmospheric disturbances [7]. Usually it is disturbed aircraft flight by wind, and turbulence.
During the trip, and these patients usually suffer the impact of large unwanted trip on the variables (height, velocity, acceleration and so on). The atmospheric disturbances that were applied as inputs to the model are pressure surface fluctuations, vertical gusts and horizontal gust. We added a white noise as an external atmospheric disturbance to the autopilot longitudinal dynamic as shown in Figure (5).

\section{THE EFFECT OF PID CONTROLLER ON AUTOPILOT SYSTEM}

The Proportional - Integral - Derivative (PID) controller works the wide plurality of the control system in the world. It has been reported that more than $95 \%$ of the control units in industrial emissions monitoring processes of PID type applications as other controls do not match the simplicity, functionality and clear, application and ease of use provided by the unit that PID control. The PID controller is used for a wide range of problems such as motor drives, flight control, and the availability of devices etc. PID controller strong and dependable efficiency of most systems if the PID parameters are altered accurately.

A PID controller is described by the following transfer function in the continuous s-domain

$$
\begin{aligned}
\mathrm{G}(\mathrm{S}) & =\mathrm{P}+\mathrm{I}+\mathrm{D} \\
& =\mathrm{Kp}+\mathrm{K}_{\mathrm{i}} / \mathrm{s}+\mathrm{K}_{\mathrm{d}} \mathrm{s} \\
\text { Or } & =\mathrm{Kp}\left(1+1 / \mathrm{T}_{\mathrm{i}} \mathrm{s}+\mathrm{T}_{\mathrm{d}} \mathrm{s}\right)
\end{aligned}
$$

Where

$K_{P}$ is the proportional gain, $K_{i}$ is the integration coefficient, $\mathrm{K}_{\mathrm{d}}$ is the derivative coefficient, $\mathrm{T}_{\mathrm{i}}$ is known as integral action time, $T_{d}$ is referred to as derivative action.

This controller has three different amendments $(\mathrm{Kp}, \mathrm{Ti}, \&$ Td), which interact with each other. For this reason, it is difficult and time-consuming to set these three parameters in order to obtain best performance according to the design specification of the system. PID autopilot has been successfully united as real-time control and online steering systems for aircraft. This is not just due to their simple structure and informal implementation, but likewise to their acceptable performances. The tuning process, whereby the optimum values of the controller parameters are achieved, is a decisive challenge [8].

Hence, the PD control, possible by combining the feedbacks through a rate-integrating gyro and a rate gyro. It was found that a larger proportional controller as well as derived was necessary to maintain the organization stable and responding promptly. It is gentle to apply and here the aim is to suppress the oscillatory effects and to minimize the considerably big settling time values. The role of PID controller in reducing the effect of atmospheric disturbance on the aircraft as a convoluted controller [9], as shown in Figure (5) below 


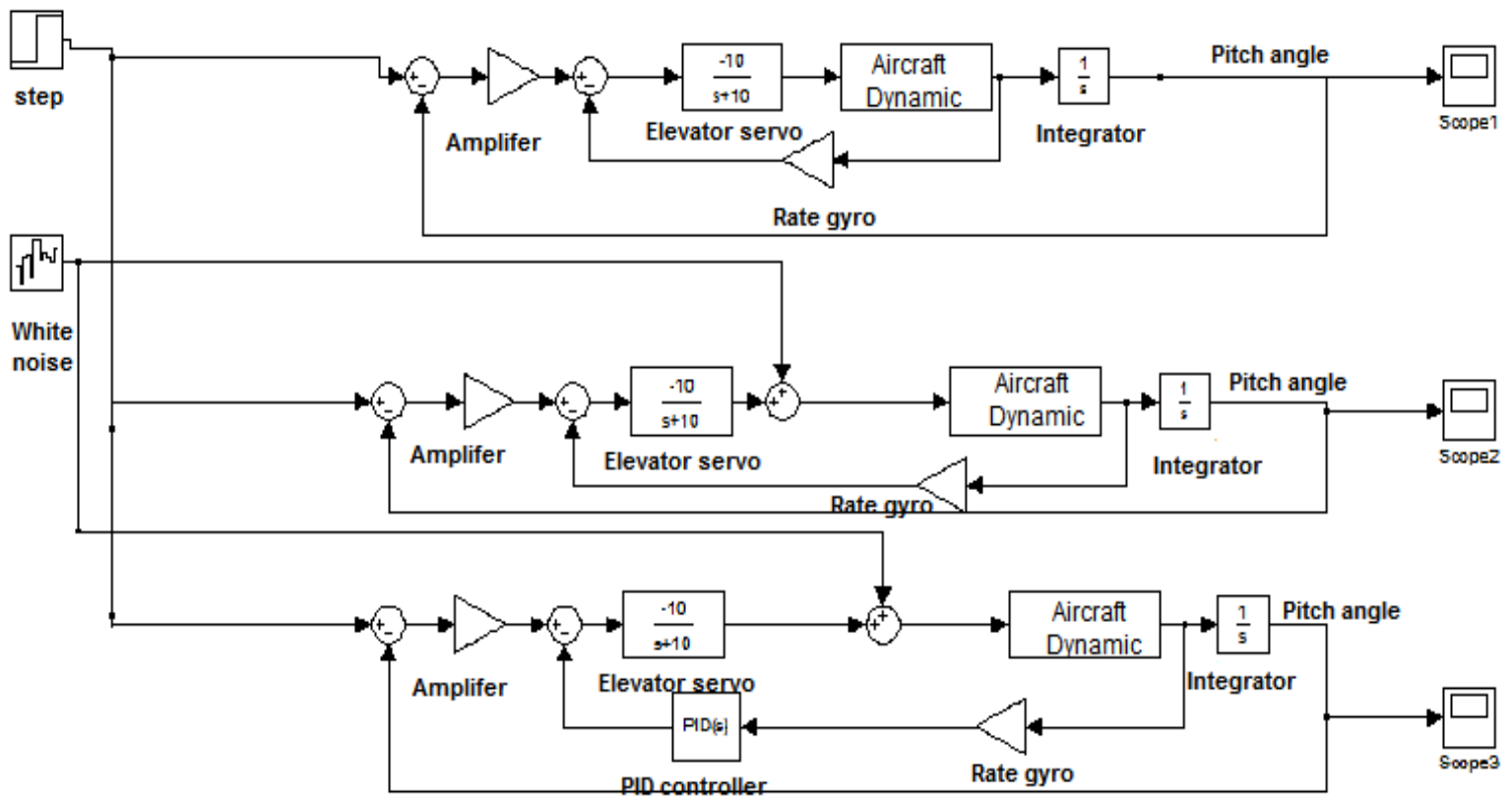

Figure (5): The Overall Control System of Pitch Angle in Longitudinal Mode with PID Control

\section{SIMULATION AND RESULTS}

In this section, it has been explained the simulation results of the autopilot system in longitudinal dynamic (pitch angle) in three cases, the first case, when the autopilot system is stable before the effect of the disturbance, then shown the impact of external factors on the stability of the system. Then in the third case explained the role of PID controller in reducing the effect of atmospheric disturbance on the aircraft. The response of pitch angle in three cases illustrated in Figures (6), (7) and (8).

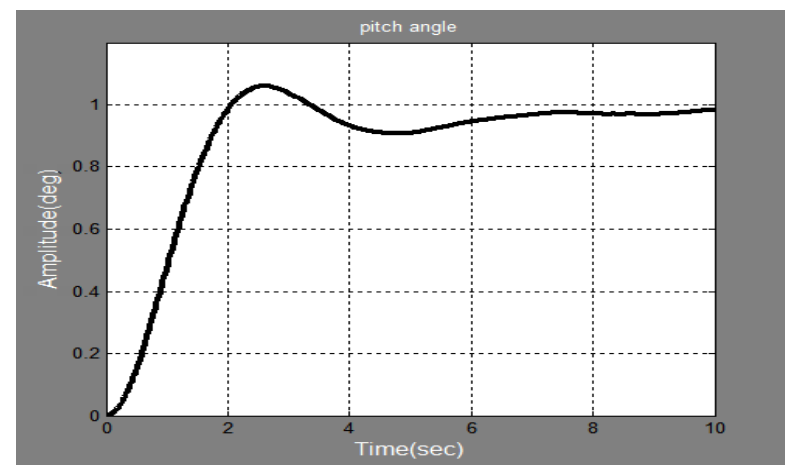

Figure (6): The response of pitch angle in stability case

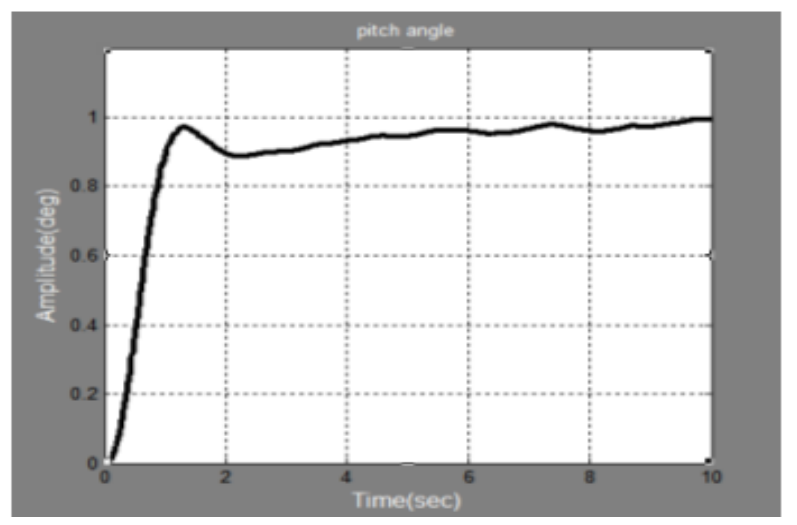

Figure (7): The response of pitch angle in disturbance case

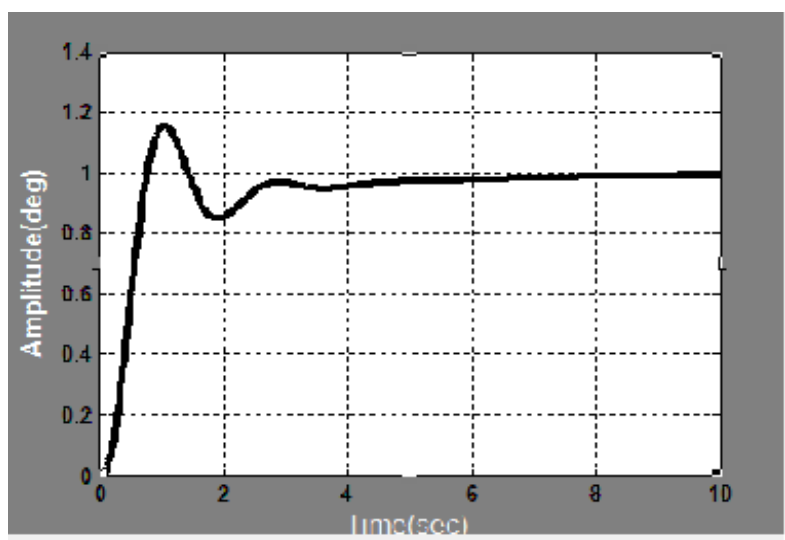

Figure (8): The response of pitch angle in PID controller case

The performance index of pitch angle in all previous cases as shows in tables (3)

Table (3): Summary of performance characteristic of pitch angle

\begin{tabular}{|c|c|c|c|}
\hline \multirow{2}{*}{$\begin{array}{c}\text { Performance } \\
\text { Index }\end{array}$} & \multicolumn{3}{|c|}{ Pitch angle } \\
\cline { 2 - 4 } & Stable & $\begin{array}{c}\text { Atmospheric } \\
\text { Disturbances }\end{array}$ & $\begin{array}{c}\text { PID } \\
\text { Controller }\end{array}$ \\
\hline $\begin{array}{c}\text { Delay time, } \\
\mathrm{t}_{\mathrm{d}}(\mathrm{sec})\end{array}$ & 0.463 & unstable & 1.0 \\
\hline $\begin{array}{c}\text { Rising time, } \\
\mathrm{t}_{\mathrm{r}}(\mathrm{sec})\end{array}$ & 0.7717 & unstable & 1.985 \\
\hline $\begin{array}{c}\text { Setting time, } \\
\mathrm{t}_{\mathrm{s}}(\mathrm{sec})\end{array}$ & 4.0 & $8.6 \mathrm{~s}$ & 7.0 \\
\hline Peak time, $\mathrm{t}_{\mathrm{p}}(\mathrm{sec})$ & 1.031 & unstable & 2.6 \\
\hline $\begin{array}{c}\text { Maximum } \\
\text { overshoot } \mathrm{m}_{\mathrm{p}}\end{array}$ & 1.154 & unstable & 1.057 \\
\hline $\begin{array}{c}\text { Steady state } \\
\text { error, ess }\end{array}$ & 0.0085 & 0.0127 & 0.0178 \\
\hline
\end{tabular}




\section{CONCLUSION}

In this paper, as a first measure, the autopilot longitudinal dynamic of jet transport aircraft has been discussed and then was added atmospheric disturbances as a white noise block and indicate their shock on the stableness of the organization, but autopilot systems and, more approximately, flight control systems are difficult organizations and are mostly systems. PID controller is used to help the organization in responding effectively. The effects of PID controller have been illustrated when it is adding to the autopilot system. PID controller is much more desirable because of its high response time, low overshoot, and low steady state error. As a future idea for this paper it is possible used PID controller in lateral mode in autopilot to control the effect of disturbance in Yaw and Roll angles.

\section{REFERENCES}

[1] Michael V. Cool. 2007. Flight Dynamic Principle.2 $2^{\text {nd }}$, Published by Elsevier Ltd.

[2] K. Turkoglu, U. Ozdemir, M. Nikbay, E. Jafarov. 2008. PID parameter optimization of a UAV longitudinal Flight Control system. World Academy of Science, Engineering and Technology.

[3] Rauw, Marc. 2001. A Simulink Toolbox for Flight Dynamics and Control Analysis. Marc Rauw.

[4] David F. Anderson and Scott Eberhardt. 2001. Understanding Flight. New York. McGraw- Hill.

[5] R. C. Nelson. 1998 .Flight stability and automatic control. New York. McGraw-Hill, 2nd edition.

[6] John H. Blake lock. 1991. Automatic Control of Aircraft and Missiles. $2^{\text {nd }}$ edition, A Wiley Interscience publication.

[7] Uma in Ahsun. 1996. Dynamic characterization and Active Control of Unstarts in a Near-Isentropic Supersonic Intet. Lahore Pakistan.

[8] B. Kada, Y. Ghazzawi.2011. Robust PID Controller Design for an UAV Flight Control System. San Francisco, USA.

[9] Ashish Tewari. 2007. Atmospheric and Space Flight Dynamics Modeling and Simulation with meth lab and Simulink. Birkhauser Boston. 